\title{
A model of sediment transport under the influence of surface bioturbation: generalisation to the facultative suspension-feeder Scrobicularia plana
}

\author{
Francis Orvain* \\ CREMA (CNRS-IFREMER UMR 10), Centre de Recherche sur les Ecosystèmes Marins et Aquacoles de L'Houmeau, \\ Place du séminaire, BP 5, 17137 L'Houmeau, France
}

Present address: LBBM, Laboratoire de Biologie et Biotechnologie Marine, Université de Caen, Esplanade de la paix BP 5186, 14032 Caen cedex, France

\begin{abstract}
Flume experiments were designed to study how sediment erodibility was modified by the facultative suspension-feeder Scrobicularia plana living at different densities in sediment beds of various degrees of compaction. Two separate erosion phases were identified from the resuspension kinetics: (1) erosion of an unconsolidated surficial layer (i.e. fluff layer) and (2) the subsequent bed erosion. S. plana were found to influence both erosion phases: (1) erosion rates of the fluff layer were controlled by bioturbation activities, the extents of which were influenced by bivalve density and the degree of compaction of the sediments, and (2) critical thresholds of the subsequent bed erosion decreased as clam density increased, likely due to depressions in the sediment bed that were created by siphon activity. A 1-dimensional vertical model was modified to incorporate the effects of S. plana on fluff layer formation through pseudofaeces production. The modifications to the model and results are compared to a similar approach for Hydrobia ulvae published earlier, and are discussed with respect to the definition of functional groups of bioturbators in sediment transport models. By discussing effects of spatial grouping and analogies to other organisms, this study shows how the influence of one species on sediment resuspension may be generalised and used for model descriptions of other species of the same behavioural type. Model developments on pseudofaeces production show that there are asymmetric effects generated over time and by bivalve density for $S$. plana, which do not occur for H. ulvae.
\end{abstract}

KEY WORDS: Intertidal mudflat $\cdot$ Scrobicularia plana $\cdot$ Bioturbation $\cdot$ Sediment transport $\cdot$ Functional groups $\cdot$ Model $\cdot$ Resuspension

\section{INTRODUCTION}

Over the past few decades, benthic marine ecologists have made great advances in understanding bioturbation and its role in sediment transport. There is general agreement that macrofauna can be divided into 2 functional groups: sediment stabilisers and destabilisers (Rhoads \& Young 1970, Rhoads 1974, Widdows et al. 1998). However, such broad classification is insufficient for quantitative descriptions of animal-sediment relationships and also to account for the immense diversity of actions exerted by macrofauna on sediment stability (Rhoads \& Young 1970, Rhoads 1974, Nowell et al. 1981, Grant 1983, Jumars \& Nowell 1984, Davis 1993, Grant \& Daborn 1994, Hall 1994, Graf \& Rosenberg 1997, Shaikh et al. 1998, Widdows et al. 1998).

Biological activities can alter many physical properties of bottom sediments, such as erosion resistance, water content, shear strength, bed roughness, sediment structure, grain size (by pelletisation), or sediment binding (through mucus production). These 
physical variables, which are potentially subjected to biological modification, are traditionally listed in isolation (e.g. Rhoads 1974, Jumars \& Nowell 1984, Hall 1994). However, all of these disturbances can be considered as various aspects of the same single process: fluff layer creation and erosion. The fluff layer is constituted by aggregates disconnected from the consolidated sediment, produced by deposit feeders and very easily eroded. This term also refers to sedimentation of phytodetritus aggregating on the sea floor (Beaulieu \& Smith 1998), but, in our case, this term is strictly used to describe a benthos-generated surface layer. For example, the common mud snail Hydrobia ulvae disrupts the upper layers of sediment while crawling, and this effect induces a decrease in bed resistance. As a result, this leads to an enhancement of the rates of fluff layer erosion in the presence of actively crawling snails (Blanchard et al. 1997, Andersen et al. 2002, Orvain et al. 2003). Particle binding is also a result of the large quantities of mucus that are secreted by this motile gastropod within the fluff layer, and mucus must contribute to the gradual disruption by tracks during fluff layer erosion, some of the tracks being able to resist strong currents, while others are rapidly eroded (Orvain et al. 2003). Moreover, faecal pellets can constitute a large part of the fluff layer material (Andersen 2001). Fluff layer creation may also be associated with an increase in local bed roughness due to surface irregularities (such as deposits of pseudofaeces, burrows, or tracks) created during bioturbation. Such an effect may be responsible, at least in part, for the low thresholds of fluff layer erosion. To summarise, $H$. ulvae produces a fluff layer, which encompasses tracks, mucus and faecal pellets and which is very easily eroded. In addition to fluff layer formation, $H$. ulvae enhance bed roughness via their shells, when they are exposed to strong currents, and this effect could increase bed erosion.

The distinction between the effects on fluff layer erosion and on bed erosion are therefore sufficient to account for all the effects of a single species on sediment resuspension (Orvain et al. 2003). We may assume that this distinction, between the effects on fluff layer and bed erosion, is also appropriate for other species, even if they belong to different functional groups. For example, the bivalve Scrobicularia plana, a facultative suspension feeder, collects food by siphoning sediment from the surface and from subsurface sediments surrounding its semi-permanent burrow during emersion periods (Hughes 1969), while it is a suspension feeder during immersion periods. During low-tide conditions, withdrawal of the inhalant siphon creates holes surrounded by star-shaped structures at the entrance to burrows, altering bed roughness and possibly the critical shear stress for bed erosion. More- over, large amounts of pseudofaeces are regularly ejected by the inhalant siphon, while faeces are ejected from the exhalant siphon. Faeces and pseudofaeces produced by this bivalve are eroded more easily than ambient sediments, and they constitute a fluff layer (Nowell et al. 1981, Widdows et al. 1998). Orvain et al. (2003) have proposed a 1-dimensional vertical model describing the influences of Hydrobia ulvae on sediment erosion, by separating the effects of bioturbation on the fluff layer and bed erosion. The aim of the present study was to examine how this model, which was developed for $H$. ulvae, can be applied to $S$. plana. This modelling exercise was done on the basis of flume experiments, in order to evaluate the effects of $S$. plana on sediment properties. A series of flume experiments was completed using homogenised mudflat sediments from a study site in Marennes-Oléron Bay on the Atlantic coast of France. In these experiments, cohesive sediment erodibility was estimated as a function of bivalve density over a range of sediment dry densities. Additional details about the study site, experimental procedures and model development can be found in an earlier publication (Orvain et al. 2003); only a summary of the flume methods is presented here. Finally, simulations of the development and erosion of the fluff layer and erosion of the underlying sediment bed in the presence of $S$. plana are discussed and compared to previous studies on sediments bioturbated by $H$. ulvae.

\section{MATERIALS AND METHODS}

Mudflat sediments were collected from the Montportail-Brouage mudflat in Marennes-Oléron Bay (SW France). Sediments were collected from 10 to $20 \mathrm{~cm}$ below the surface, in order to avoid contamination with active diatoms during our experiments. The mud was sieved $(<1 \mathrm{~mm})$ to remove the macrofauna, without additional water, and then homogenised regularly during a storage period of 2 mo in the darkness at $10^{\circ} \mathrm{C}$. This stock of sediment was used in all the experiments. The $<63 \mu \mathrm{m}$ fraction accounted for $92 \%$ by dry weight, and the grain size averaged between 1 and $6 \mu \mathrm{m}$ (Galois et al. 2000).

Experiments were organised in a 2-way design with 2 crossed factors (i.e. sediment dry density and Scrobicularia plana density). Four treatments for bivalve density were tested $(0,36,72$ or 168 individuals were added to sediment; corresponding densities were 0 , 107, 215 and 502 ind. $\mathrm{m}^{-2}$ ), and 2 modalities were tested for sediment (denoted 'compact' and 'fluid', corresponding to average dry densities of $535 \pm 23$ and $374 \pm 10 \mathrm{~kg} \mathrm{~m}^{-3}$, respectively). Two replicates of the complete $4 \times 2$ factorial design were conducted in a random sequence of 16 flume experiments. 
The sediments were inoculated with microphytobenthos to stimulate the deposit-feeding activities of bivalves. Sediments were diluted with a volume of seawater to which $100 \mathrm{~cm}^{3}$ of a fresh diatom concentrate mixture was added. The procedure for the preparation of the fresh diatom mixture from the natural multispecific assemblage of the Montportail-Brouage mudflat (Marennes-Oléron Bay, France) is described in Orvain \& Sauriau (2002).

Large trays (height: $13.5 \mathrm{~cm}$; length: $90 \mathrm{~cm}$; width: $40 \mathrm{~cm}$; surface area: $0.36 \mathrm{~m}^{2}$ ) were loaded with a compact mud layer (8 $\mathrm{cm}$ high) from the standing stock. Scrobicularia plana individuals, which had been collected from the Marennes-Oléron Bay, were placed at the sediment surface by vertical orientation of the anterior-posterior axis of their shells, which is their natural position in sediment (Hughes 1969). If the animals were unable to bury themselves, they were replaced. The sediment surface was then smoothed, and all trays that were prepared at the same time were installed in tidal tanks filled with seawater (salinity of 30 to $31 \mathrm{psu}$ and temperature regulated at $18^{\circ} \mathrm{C}$ ) and subjected to an alternating emersion-immersion cycle (16:8 h). The experimental period lasted 2 wk (1 experiment $\mathrm{d}^{-1}$ ), during which deposit feeding was observed, with siphon activity leaving the familiar star-shaped marks and pseudofaeces cones on the surface of the mud.

At the beginning of a simulated low tide, 1 tray was removed from a tidal tank and mud filling was rounded off with 'compact' or 'fluid' sediments, as appropriate, until a final sediment depth of $13.5 \mathrm{~cm}$ was obtained to adjoin the container edges. The mud surface was smoothed carefully to avoid local irregularities that could bias resuspension results. Trays were transferred to the flume test section, and the flume was filled with $2 \mu \mathrm{m}$ filtered seawater (same salinity and temperature) until a thin water layer (5 mm) appeared on the sediment surface. The film of water over the mud was necessary for the animals to respire and ingest the sediment (Hughes 1969); this condition exists in most of their habitats throughout natural low tide. After simulating a low-tide period of $5 \mathrm{~h}$, the flume was filled further with seawater until a water depth of $15 \mathrm{~cm}$ was attained over the test section.

We tested 4 bivalve densities by manipulating 0,36 , 72 , or 168 individuals that were regularly distributed among 6 generations. Bivalve year classes were separated by the number of winter rings, and 6 age classes were distinguished (i.e. $0,1,2,3,4,>5$ yr). After each flume experiment, dead animals were counted to subtract them from overall bivalve density and live animals were pooled to estimate the length-weight relationship of the whole population. Shell lengths were estimated using a micrometer ( $0.1 \mathrm{~mm}$ accuracy), and ash-free dry weights were measured from the weight difference between dry flesh weight (obtained after drying at $60^{\circ} \mathrm{C}$ during $3 \mathrm{~d}$ ) and ash biomass (obtained after burning at $550^{\circ} \mathrm{C}$ during $5 \mathrm{~h}$ ). The following length-weight relationship was obtained: AFDW = $4.84 \times 10^{-6} L^{2.744}\left(\mathrm{~N}=156, \mathrm{r}=0.917, F_{1,154}=819, \mathrm{p}<\right.$ 0.001), where AFDW is ash-free dry weight (in g) and $L$ is shell length (in $\mathrm{mm}$; range: 16.0 to $36.0 \mathrm{~mm}$ ).

The HYDROBIOS benthic flume (Orvain et al. 2003) is a $3 \mathrm{~m}$ long recirculating-flow system in the vertical plane, which generates free-stream velocities of up to $0.6 \mathrm{~m} \mathrm{~s}^{-1}$ (with $0.01 \mathrm{~m} \mathrm{~s}^{-1}$ accuracy) and bed shear stress $\left(\tau_{f}\right)$ of up to $1.6 \mathrm{~Pa}$ for a flat muddy bed placed in the test section. As currently practised with devices measuring sediment erodibility, known bed shear stresses are applied incrementally and the bed response is recorded through turbidity measurements. During each shear stress step, the concentration of suspended particulate matter (SPM, in $\mathrm{kg} \mathrm{m}^{-3}$ ) in the flume was monitored at $15 \mathrm{~s}$ intervals with an optical backscatter sensor (OBS) that was placed downstream of the test section. The OBS was calibrated against water samples taken at the same place in the flume, and calibration curves were produced for each experimental run $\left(\mathrm{N}=384, \mathrm{r}=0.984, F_{1,382}=11504, \mathrm{p}<\right.$ 0.001). A total of 80 data points were collected for each 20 min shear stress step. A running average $(\mathrm{N}=15)$ was fitted for each separate 80-data-point time step without any overlap between steps. Resuspension data were converted into sediment mass eroded per unit area $\left(M\right.$, in $\left.\mathrm{kg} \mathrm{m}^{-2}\right)$ according to the formula: $M=$ $\operatorname{SPM}(V / S)$, where $V$ is the flume volume $\left(1.16 \mathrm{~m}^{3}\right)$ and $S$ is the test section surface area $\left(0.36 \mathrm{~m}^{2}\right)$.

The critical threshold for erosion $\left(\tau_{\mathrm{b}}\right)$ was estimated by finding the onset of a sharp increase in the erosion rate. This point of incipient erosion can be detected in erosion kinetics from the baseline divergence of fluff layer erosion on the $M$ time series. However, the distinction was sometimes difficult between fluff layer and bed erosion, especially when a high quantity of sediment was involved in fluff layer erosion. Thus, a more rigorous method of estimating $\tau_{\mathrm{b}}$ was established.

Theoretically, bed erosion rates gradually increase as a function of shear stress, and the largest increase in erosion rate is obtained at $\tau_{\mathrm{b}}$. This relative rate of increase of $M$ between 2 steps can be expressed as the criterion:

$$
X_{i}=\frac{\tilde{M}_{i+1}-\tilde{M}_{i}}{\tilde{M}_{i}-\tilde{M}_{i-1}}
$$

where $\tilde{M}_{i-1}, \quad \tilde{M}_{i+1}$ and $\tilde{M}_{i}$ are the averaged 80 data points of $M$ within the steps $i-1, i$ and $i+1$. The maximum value of the criterion $X_{i}$ provided the first shear stress exceeding the critical threshold. Therefore, $\tau_{\mathrm{b}}$ 
Table 1. Characteristics of the sediment beds for each experimental run. The slash indicates no erosion threshold was measured

\begin{tabular}{|lccc|}
\hline $\begin{array}{c}\text { Dry density } \\
\left(\rho_{\mathrm{d}}, \mathrm{kg} \mathrm{m}^{-3}\right)\end{array}$ & $\begin{array}{c}\text { Bivalve } \\
\text { density } \\
\left(\text { ind. } \mathrm{m}^{-2}\right)\end{array}$ & $\begin{array}{c}\text { Chl } a \\
\text { Content } \\
\left(\mu \mathrm{g} \mathrm{g}^{-1} \mathrm{DW}\right)\end{array}$ & $\begin{array}{c}\text { Erosion } \\
\text { threshold } \\
\left(\tau_{\mathrm{b}}, \mathrm{Pa}\right)\end{array}$ \\
\hline $377 \pm 1$ & 0 & $7.8 \pm 0.1$ & $/$ \\
$368 \pm 2$ & 0 & $8.4 \pm 0.1$ & $/$ \\
$387 \pm 13$ & 107.7 & $10.0 \pm 0.2$ & 1.08 \\
$378 \pm 1$ & 107.7 & $8.4 \pm 0.3$ & 1.28 \\
$359 \pm 1$ & 215.3 & $8.7 \pm 0.1$ & 0.74 \\
$383 \pm 1$ & 215.3 & $8.5 \pm 0.2$ & 0.90 \\
$377 \pm 13$ & 472.5 & $9.2 \pm 0.1$ & 0.59 \\
$360 \pm 2$ & 490.4 & $8.8 \pm 0.1$ & 0.35 \\
$562 \pm 8$ & 0 & $8.2 \pm 0.2$ & $/$ \\
$527 \pm 7$ & 0 & $9.2 \pm 0.2$ & $/$ \\
$522 \pm 8$ & 107.7 & $8.3 \pm 0.3$ & $/$ \\
$556 \pm 0$ & 107.7 & $7.8 \pm 0.2$ & $/$ \\
$535 \pm 3$ & 215.3 & $8.2 \pm 0.2$ & $/$ \\
$580 \pm 12$ & 215.3 & $7.9 \pm 0.3$ & 0.90 \\
$511 \pm 4$ & 502.4 & $8.2 \pm 0.1$ & $/$ \\
$525 \pm 7$ & 502.4 & $9.5 \pm 0.4$ & 0.59 \\
& & & \\
\hline
\end{tabular}

bed wrenching. The influence of sediment dry density on $\tau_{\mathrm{b}}$ could not be analysed in experiments without animals, since no erosion was measured in these cases (Figs. 1B \& 2B).

The effects of Scrobicularia plana density on critical thresholds could be studied only for the fluid-sediment series (Fig. 1B), because the magnitude of the shear stress was too low to observe any bed erosion for the compact-sediment series, except for 2 experiments from this series (Fig. 2B). The $\tau_{\mathrm{b}}$ values of the fluid-sediment series decreased as a function of bivalve density following a negative exponential pattern (Fig. 3). This suggests that the star-shaped structures formed by the siphon activity of $S$. plana positively influenced erosion. Bed erosion occurred by wrenching large pieces of mud from the holes at the centres of these star-shaped structures. Bed material was released at high concentrations into the water of the experimental system; however, bed erosion rates did not depend on bivalve density. The bioturbation effects and water contents both interacted positively was computed as the mean of $\tau_{i-1}$ and $\tau_{i \text {. }}$ The critical shear stress for fluff erosion $\tau_{\text {fluff }}$ was estimated following the same procedure by selecting data before the critical threshold for erosion had been attained (i.e. on $M$ data, for which $\tau_{f}<\tau_{b}$ ).

\section{RESULTS}

\section{Resuspension of sediments}

No erosion was obtained in controls without bivalves. With the bivalves, 2 erosion phases can be identified on the basis of the resuspension kinetics (Figs. 1 \& 2): (1) fluff layer erosion, with relatively low erosion rates, and (2) potential subsequent bed erosion that was recognised by a sharp increase in eroded mass. Both erosion phases had critical thresholds: (1) The critical threshold for the fluff layer $\left(\tau_{\text {fluff }}\right)$ was estimated as the point at which fluff layer erosion started in time-series plots (Figs. 1A \& 2A); no difference appeared between critical thresholds in the presence of bivalves. Critical thresholds ranged between 0.07 and $0.13 \mathrm{~Pa}$, and are consistent with the observation that loose aggregates began to move and roll over the sediment bed at a shear stress of 0.13 Pa. (2) The critical threshold for bed erosion $\left(\tau_{b}\right)$ was estimated by detecting the highest rate of increase of the eroded mass of sediment (Figs. 1B \& 2B, Table 1). Values were highly variable and consistent with the observation of
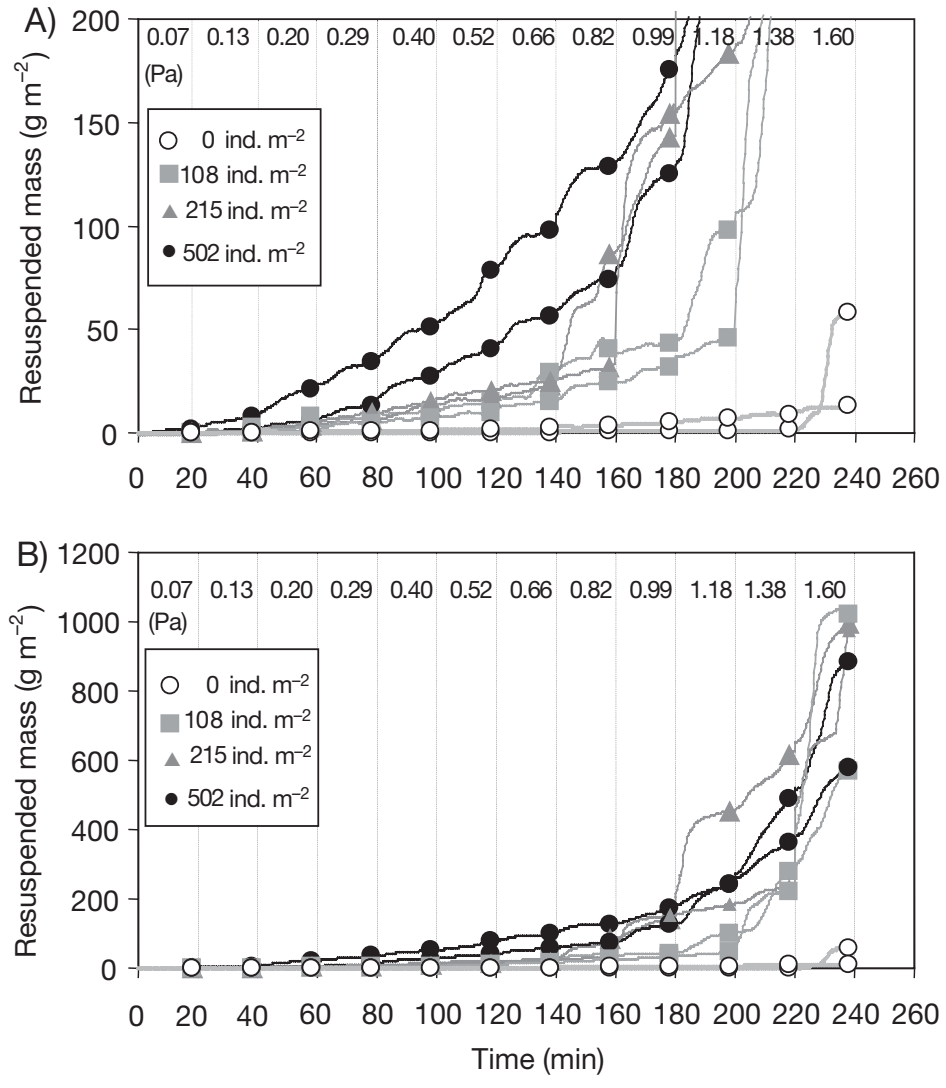

Fig. 1. Eroded mass as a function of time in response to increasing bed shear stress applied step-by-step to fluid sediments: (A) focus on fluff layer erosion, with a $y$-axis scale of 0 to $200 \mathrm{~g}$ $\mathrm{m}^{-2}$, and (B) overall view of erosion kinetics 

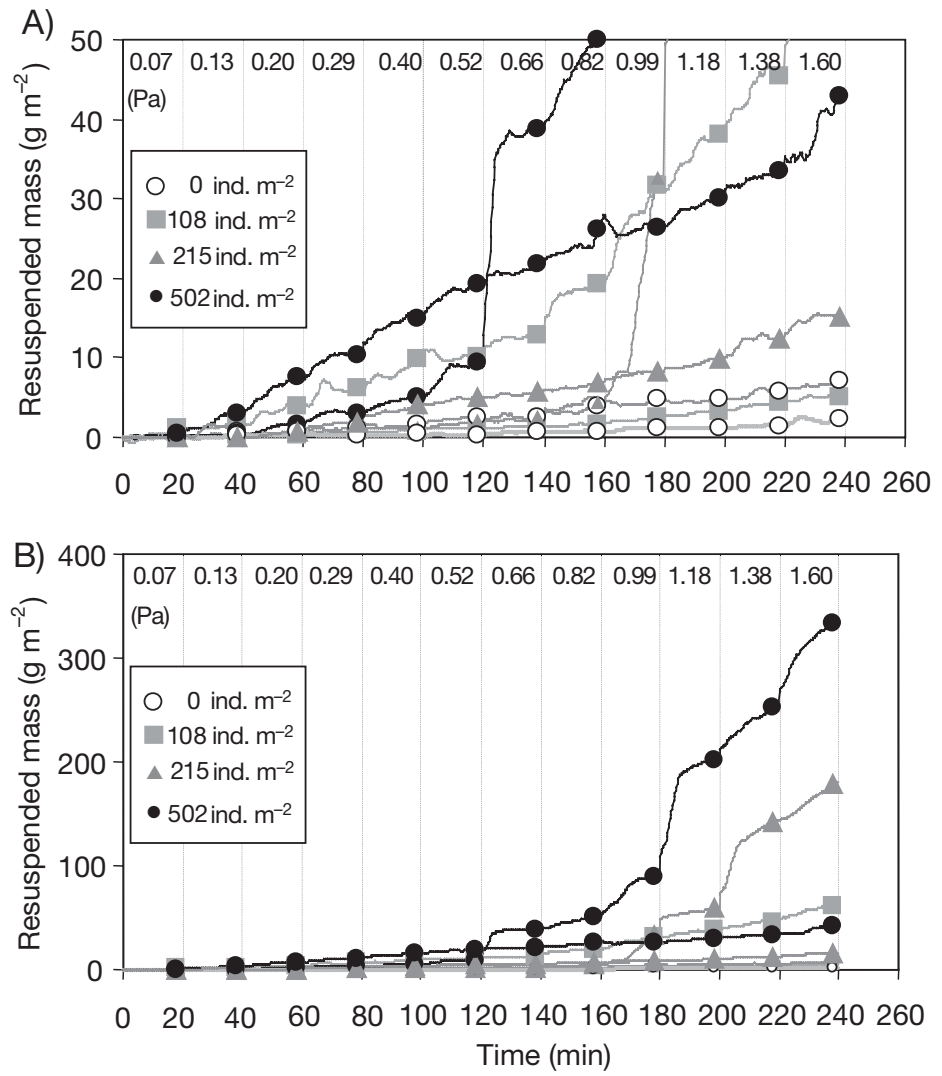

Fig. 2. Eroded mass as a function of time in response to increasing bed shear stress applied step-by-step to consolidated sediments: (A) focus on fluff layer erosion, with a $y$-axis scale of 0 to $50 \mathrm{~g} \mathrm{~m}^{-2}$, and (B) overall view of erosion kinetics

on $\tau_{\mathrm{b}}$. Although nothing can be said about the compact-sediment series concerning $\tau_{\mathrm{b}}$, the fact that no bed erosion (except in 2 cases for the highest clam densities) took place suggests the important role of water content in governing bed resistance to erosion.

The increase in the fluff layer erosion rates appeared to be a linear function of shear stress most of the time (Figs. 1A \& 2A). However, when no bed erosion took place (i.e. for some curves of the compact-sediment series, Fig. 2B), the fluff layer erosion phase was uninterrupted up to the highest shear stress of 1.6 Pa and erosion rates had a tendency to decrease versus shear stress. A plateau should have occurred if higher shear stresses had been applied in the experiments.

The presence of Scrobicularia plana increased resuspension at all shear stresses during fluff layer erosion. Bivalve-density effects were more apparent on erosion rates for the soft-sediment series (Figs. 1A \& 2A). Erosion rates depended on bivalve activities, which were likely to be stimulated by and correlated to the sediment water content.

\section{Model of sediment transport}

The equations and coefficients of the model are summarised in Table 2. The 1-dimensional vertical model belongs to a series of models with a similar design and including 2- or 3-dimensional versions (e.g. Brenon \& Le Hir 1999, Cugier \& Le Hir 2002). The model solves equations by using iterative calculations (tridiagonal matrix) of sediment exchange between vertical layers involving mass balance. The sediment column is conceptualised as being divided into vertical layers (Fig. 4); sediment enters and leaves the water column according to bed erosion and deposition terms with respect to the mass equilibrium condition (see Eq. $1, E_{\text {bed }}$ and $D$, respectively, in $\mathrm{kg} \mathrm{m}^{-2} \mathrm{~s}^{-1}$ ). The dry density of each sediment layer $\left(\rho_{\mathrm{d}}\right)$ is a fixed input in the model; however, the layer thickness may change depending on the magnitude of the erosion and deposition terms. In this model approach, the fluff layer is defined as a separate sediment compartment with its own erosion flux and density $\left(E_{\text {fluff }}\right.$ in $\mathrm{kg} \mathrm{m}^{-2} \mathrm{~s}^{-1}$, and $\rho_{\text {fluffi }}$ see Fig. 4). The output variable of the model is the eroded mass $M$, which varies over time as the sum of all component fluxes:

$$
\frac{\mathrm{d} M}{\mathrm{~d} t}=E_{\text {fluff }}+E_{\text {bed }}-D
$$

During fluff layer erosion (and in the absence of bed erosion), $E_{\text {bed }}$ and $D$ are 0 and $E_{\text {fluff }}$ accounts for all fluctuations of $M$.

\section{Fluff layer erosion}

The initial quantity of sediment within the fluff layer compartment $\left(A_{t=0}\right.$, in $\mathrm{kg} \mathrm{m}^{-2}$, before resuspension has occurred) depends on both the bivalve density and the

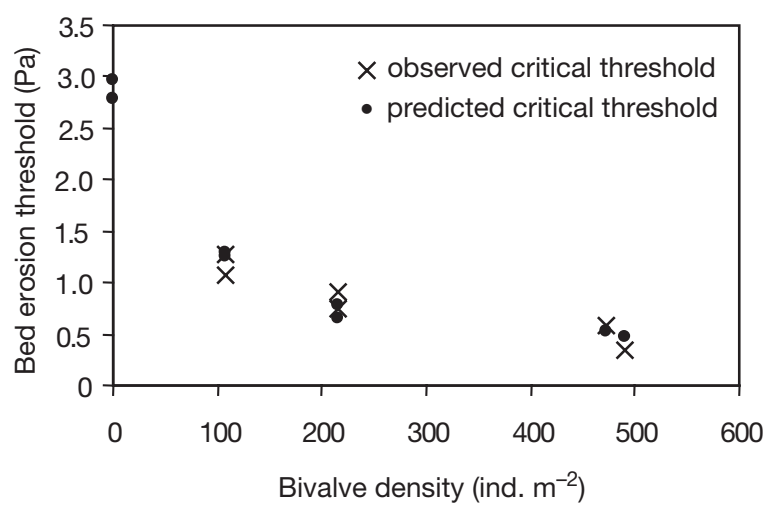

Fig. 3. Sediment bed erosion threshold (critical shear stress $\tau_{\mathrm{b}}$ ) plotted against Scrobicularia plana density for the experiments with fluid sediments 
Table 2. Model variables, equations and coefficient values used for Scrobicularia plana

\begin{tabular}{|c|c|c|c|c|}
\hline & Value & Unit & Description & Origin \\
\hline \multicolumn{5}{|c|}{ FORCING VARIABLES } \\
\hline$\sigma_{\mathrm{f}}$ & Function of time (step-by-step) & $\mathrm{Pa}$ & Bed shear stress & \\
\hline$n_{i}$ & Function of experiment & ind. $\mathrm{m}^{-2}$ & Bivalve density per size class $i$ & Measured \\
\hline$L_{i}$ & Function of experiment & $\mathrm{mm}$ & Mean shell length of size class $i$ & Measured \\
\hline$\rho_{d}$ & Function of experiment & $\mathrm{kg} \mathrm{m}^{-3}$ & Sediment dry density & Measured \\
\hline$W$ & Derived from $\rho_{d}$ & $\%$ & Sediment water content & \\
\hline
\end{tabular}

\section{STATE VARIABLES}

\begin{tabular}{|c|c|c|c|}
\hline$\frac{\mathrm{d} M}{\mathrm{~d} t}$ & $\frac{\mathrm{d} M}{\mathrm{~d} t}=E_{\mathrm{fluff}}+E_{\mathrm{bed}}-D$ & $\mathrm{~kg} \mathrm{~m}^{-2} \mathrm{~s}^{-1}$ & Eroded mass per unit area and per second \\
\hline$\frac{\mathrm{d} A_{t}}{\mathrm{~d} t}$ & $\frac{\mathrm{d} A_{t}}{\mathrm{~d} t}=-E_{\text {fluff }}$ & $\mathrm{kg} \mathrm{m}^{-2} \mathrm{~s}^{-1}$ & Aggregate quantity in fluff layer eroded per second \\
\hline
\end{tabular}

\section{FLUFF LAYER EROSION FUNCTIONS AND COEFFICIENTS}

Pseudofaeces production: $\mathrm{PF}=a_{\mathrm{PF}} \times L_{i}^{{ }_{\mathrm{PF}}}$

\begin{tabular}{|c|c|c|c|c|}
\hline$\overline{a_{\mathrm{PF}}}$ & $1.654 \times 10^{-8}$ & $\mathrm{~kg}$ expulsion ${ }^{-1}$ ind. $^{-1}$ & L-dependent coefficient & Hughes (1969) \\
\hline$b_{\mathrm{PF}}$ & 2.446 & - & L-exponent coefficient & Hughes (1969) \\
\hline
\end{tabular}

Pseudofaeces expulsion: $\quad X=a_{X} \times W^{b_{X}}$

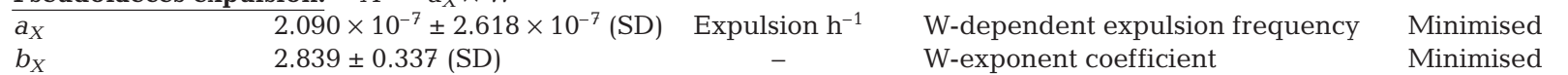

Fluff layer formation: $\quad A_{t=0}=t \times X \times \sum_{i=1}^{p} n_{i} \times \mathrm{PF}$

$\begin{array}{lllll}p & 6 & - & \text { Number of size class }(i) & \text { Fixed }\end{array}$

Fluff layer erosion: $\quad E_{\text {fluff }}=\alpha \times A_{t} \times\left(\frac{\tau_{f}}{\tau_{\text {fluff }}}-1\right)$ when $\tau_{f}>\tau_{\text {fluff }}$, else $E_{\text {fluff }}=0$

$\alpha \quad 7.725 \times 10^{-5} \pm 4.807 \times 10^{-5}(\mathrm{SD}) \quad \mathrm{s}^{-1} \quad$ Erosion coefficient $\quad$ Minimised

$\tau_{\text {fluff }} \quad 0.118 \quad$ Pa $\quad$ Critical shear stress for fluff $\quad$ Measured

\section{GENERAL BED EROSION FUNCTIONS AND COEFFICIENTS}

\section{Critical shear stress for bed erosion:}

$$
\begin{aligned}
& \tau_{b}(0)=a_{\tau} \times \rho_{d} b_{\tau} \\
& \tau_{b}=\left(\tau_{b}(0)-\frac{\tau_{b}(0)}{\omega}\right) \times \exp ^{-\theta n}+\frac{\tau_{b}(0)}{\omega}
\end{aligned}
$$

$\begin{array}{llcl}a_{\tau} & 1.06 \times 10^{-6} & \text { Pa } & \rho_{\mathrm{d}} \text {-dependent coefficient } \\ b_{\tau} & 2.502 & - & \rho_{\mathrm{d}} \text {-exponent coefficient } \\ \omega & 3.352 & - & n \text {-dependent coefficient } \\ \theta & 4.787 \times 10^{-2} & \mathrm{~m}^{2} \text { ind }^{-1} & n \text {-dependent coefficient }\end{array}$

Orvain et al. (2003) Orvain et al. (2003) Minimised Minimised

$$
\begin{array}{ll}
\underline{\text { Bed erosion: }} & E_{\text {bed }}=E_{0} \times \rho_{\mathrm{d}}{ }^{\gamma} \times\left(\frac{\tau_{f}}{\tau_{\mathrm{b}}}-1\right) \\
E_{0} & 1.250 \times 10^{-12} \\
\gamma & 3.361 \\
\text { Deposition: } & D=W_{\mathrm{S}} \times M \times \frac{S}{V} \\
W_{\mathrm{S}} & 2.469 \times 10^{-3} \\
S & 0.33 \\
V & 1.16
\end{array}
$$

$$
\begin{array}{cl}
\mathrm{kg} \mathrm{m}^{-2} \mathrm{~s}^{-1} & \text { Erosion coefficient } \\
- & \rho_{\mathrm{d}} \text {-exponent coefficient }
\end{array}
$$

Minimised Minimised 


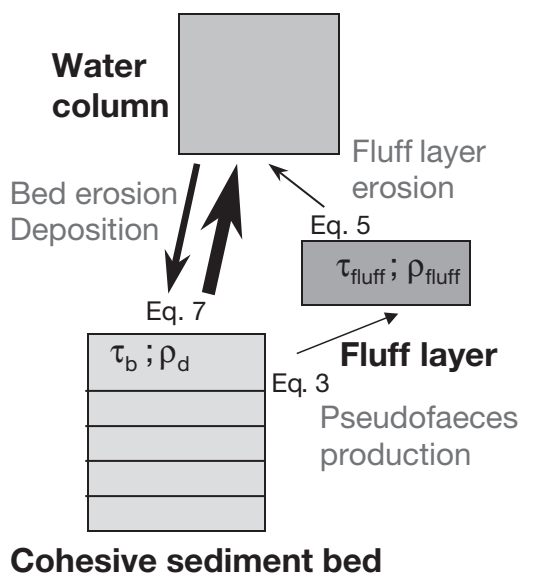

Fig. 4. Schematic representation of particle exchanges in the 1-dimensional vertical model of sediment transport

measured sediment dry density. According to Hughes (1969), pseudofaeces production in Scrobicularia plana exceeds the rate of defecation by about 300 times. Consequently, faeces production was ignored in the model and only pseudofaeces production was included.

In the experiments, animals were arranged in sediment beds with a minimum distance between neighbouring animals. No interference between the feeding activities of neighbours was observed even at the maximum density of 502 ind $\mathrm{m}^{-2}$. However, the experimental conditions were not typical of natural situations. Hughes (1970a) has interpreted the observed extension of inhalant siphons in random directions and the fact that animals took up faeces and pseudofaeces, which had been previously ejected either by the individual itself or its neighbours, as a lack of territoriality in Scrobicularia plana. Thus, in our experiments, the total quantity of produced pseudofaeces was the sum of the pseudofaeces produced by individuals, and the more complex behaviour of natural populations was not considered in our calculations.

Hughes (1969) has also observed that actively feeding animals expelled pseudofaeces every 12 to $61 \mathrm{~min}$, and he proposed an estimate for the weight of pseudofaeces produced per individual at each expulsion $(\mathrm{PF}$, in $g$ expulsion ${ }^{-1}$ ind. $\left.^{-1}\right)$ as a function of shell length $(L$, in $\mathrm{mm})$ at $16^{\circ} \mathrm{C}$, such that: $\log _{10}(\mathrm{PF})=2.4458 \times \log _{10}(L)$ -4.7814 . For convenience, this relation was converted into a power law as follows:

$$
\mathrm{PF}=a_{\mathrm{PF}} \times L_{i}^{b_{\mathrm{PF}}}
$$

where $L_{i}$ is the mean shell length (in mm) of generation $i$. The parameters $a_{\mathrm{PF}}$ and $b_{\mathrm{PF}}$ are both empirical parameters.

By using the individual production of pseudofaeces and the specific density of animals $\left(n_{i}\right.$ in ind. $\left.\mathrm{m}^{-2}\right)$ of each generation $i$, we extrapolated Hughes's relation to our bivalves and tested the following relationship for $t=5 \mathrm{~h}$ of simulated low tide:

$$
A_{t=0}=t \times X \times \sum_{i=1}^{p} n_{i} \times \mathrm{PF}
$$

where $X$ is the frequency of pseudofaeces expulsion per hour (expulsion $\mathrm{h}^{-1}$ ), which was assumed not to vary with animal size, and $A_{t=0}$ is the sediment quantity initially contained within the fluff layer. In order to account for the dry density dependence on fluff layer quantity and erosion, bivalves were assumed to ingest sediment more easily from fluid sediments than from compact sediments, so that the frequency of pseudofaeces expulsion $(X)$ is positively influenced by the water content $(W)$. An empirical power law accounted for the relation between $X$ and $W$ :

$$
X=a_{X} \times W^{b_{X}}
$$

The description of fluff layer erosion from Orvain et al. (2003) has been tested for Scrobicularia plana. It requires that $A_{t=0}$ be described as a single variable:

$$
\begin{gathered}
\frac{\mathrm{d} A_{t}}{\mathrm{~d} t}=-E_{\text {fluff }} \text { and } E_{\text {fluff }}=\alpha \times A_{t} \times\left(\frac{\tau_{f}}{\tau_{\text {fluff }}}-1\right) \\
\text { when } \tau_{f}>\tau_{\text {fluff' }} \text { else } E_{\text {fluff }}=0
\end{gathered}
$$

where $\alpha$ is an erosion coefficient $\left(\mathrm{s}^{-1}\right)$. As for Hydrobia $u l v a e$, an additional term $(\delta)$ was needed to include a vertical gradient for the critical threshold, $\tau_{\text {fluff, }}$ and to account for the heterogeneity in the resistance (Orvain et al. 2003). Minimisation tests revealed that this effect was not necessary for $S$. plana.

\section{Bed erosion}

Sediment bed erosion and deposition fluxes ( $E_{\text {bed }}$ and $D$, in $\mathrm{kg} \mathrm{m}^{-2} \mathrm{~s}^{-1}$, respectively) were defined as:

$$
E_{\text {bed }}=E_{0} \times \rho_{\mathrm{d}}^{\gamma} \times\left(\frac{\tau_{f}}{\tau_{\mathrm{b}}}-1\right) \text { and } D=W_{\mathrm{S}} \times \mathrm{SPM}
$$

where $\tau_{\mathrm{b}}$ is the critical shear stress $(\mathrm{Pa})$ for erosion, $E_{0}$ the erosion coefficient $\left(\mathrm{kg} \mathrm{m}^{-2} \mathrm{~s}^{-1}\right),\left(\tau_{f} / \tau_{\mathrm{b}}-1\right)$ represents the excess shear stress, $\gamma$ is an empirical coefficient for a power law dependence on dry density $\left(\rho_{\mathrm{d}}\right.$, in $\left.\mathrm{kg} \mathrm{m}^{-3}\right)$, and $W_{\mathrm{S}}$ is the settling velocity $\left(\mathrm{m} \mathrm{s}^{-1}\right)$. The bed erosion flux, $E_{\text {bed }}\left(\mathrm{kg} \mathrm{m}^{-2} \mathrm{~s}^{-1}\right)$ is expressed according to a modified version of Partheniades' (1965) formulation, where erosion rates increase with dry density. This equation was chosen because it has been found, in a parallel study, that it was the most appropriate for the mud sediment stock used for all experiments (Orvain et al. 2003).

For fine-grained abiotic sediments, the critical threshold $\left[\tau_{b}(0)\right.$, in $\left.\mathrm{Pa}\right]$ is correlated with the sediment 
concentration (Migniot 1968, Amos et al. 1997, Mitchener \& O'Brien 2001). Orvain et al. (2003) used the approach of Migniot (1968) to evaluate the relationship of $\tau_{b}(0)$ against sediment dry density $\left(\rho_{d}\right)$ for very soft sediments whose bulk properties were similar to those in the present study. This relationship is: $\tau_{\mathrm{b}}(0)=1.06 \times$ $10^{-6} \rho_{\mathrm{d}}^{2.502}$.

The bivalve-density dependence of the critical threshold (as a function of dry density) was computed using the following equation:

$$
\tau_{b}=\left(\tau_{b}(0)-\frac{\tau_{b}(0)}{\omega}\right) \times \exp ^{-\theta n}+\frac{\tau_{b}(0)}{\omega}
$$

where $\frac{\tau_{b}(0)}{\omega}$ is the minimum critical threshold (corresponding to a high bivalve density), $\theta$ ( $\mathrm{m}^{2}$ ind. $\left.{ }^{-1}\right)$ expresses the rate of decrease of $\tau_{\mathrm{b}}$ versus bivalve density and $\tau_{b}(0)$ is the maximum critical threshold when the bivalve density is 0 . The parameter $\omega$ is unitless and is a ratio applied to the critical bed shear stress to calculate the minimum value by keeping the effect of dry density dependence. This relation was chosen to provide a minimum critical threshold in relation to high bivalve densities (Fig. 3), and this equation also includes the dry density dependence on $\tau_{\mathrm{b}}$ irrespective of bivalve density, as indicated by the actual data.

\section{Model evaluation}

To simulate both erosion phases, a total of 8 parameters (see Table 2) were obtained by simultaneously minimising error in several parameters using a Simplex method (Nelder \& Mead 1965). We first intended to relate $A_{t=0}$ variations to sediment and biological variations, and minimisation tests were performed by making comparisons to data of the fluff layer erosion (i.e. data for which the bed shear stress exceeded the critical threshold for bed erosion were removed). Since the 1-dimensional vertical refinement is required only to simulate bed erosion, or the succession of fluff layer and bed erosion, a simplified version of the model was used for the initial testing of fluff layer erosion, in which only the equation for fluff layer erosion was evaluated (Eq. 5); independent values of $A_{t=0}$ were identified for each experimental run. The other parameter, $\alpha$, determines fluff erosion patterns with respect to fluff layer properties, and a single value was sufficient to reproduce the experimental runs. A total of 17 parameters were obtained by minimising error (16 independent values of $A_{t=0}$ and 1 common value of $\alpha$ ).

Very satisfactory agreements were achieved when these model estimates were compared to the experi- ment results (data not shown, $\mathrm{r}^{2}=0.885, F_{15,1559}=801$, $\mathrm{p}<0.001)$. This first minimisation test revealed that the fluff layer erosion function that was developed earlier for a sediment surface bioturbated by crawling organisms (Hydrobia ulvae) also satisfactorily estimated erosion of a sedimentary surface bioturbated by Scrobicularia plana. The variation of the mass of the fluff layer $\left(A_{t=0}\right)$ is sufficient to explain the variability in resuspension results by the model. We then searched to explain the variation of this parameter $\left(A_{t=0}\right)$ by using Eqs. 2 and 4 for pseudofaeces formation. The variation in $A_{t=0}$ estimates appeared linear when plotted against bivalve density, and regression slopes were dependent on the water content (Fig. 5). The relationship that was proposed by Hughes (Eq. 2) to calculate the pseudofaeces production as a function of the individual size of animals was directly used in the model. The 2 parameters of Eq. (2) $\left(a_{X}\right.$ and $\left.b_{X}\right)$, which describes pseudofaeces expulsion as a function of sediment water content, were minimised to reproduce the variation in $A_{t=0}$. The 3 minimised parameters $\left(\alpha, a_{X}\right.$ and $\left.b_{X}\right)$ were eventually readjusted to reproduce the kinetics of fluff layer erosion ( $M$ data) by using the complete model of fluff layer formation and erosion (Eqs. 2 to 5), and parameter standard deviations were estimated by using a bootstrap method (Efron 1979). The surface bioturbation effect (pseudofaeces production) of S. plana supplies sufficient mass to the fluff layer to account for erosion fluxes. Very good agreement between observed and predicted eroded masses was obtained by estimating 3 parameters by minimising error (Figs. 6A, 7 \& 8A).

All other parameters were calibrated on the basis of the complete eroded mass data (fluff layer erosion and general bed erosion). The 1-dimensional vertical model with bioturbation functions (Eqs. 2 to 5 ) correctly reproduces the succession in time of both erosion phases for fluid sediments (Fig. 6). The fluff layer erosion was

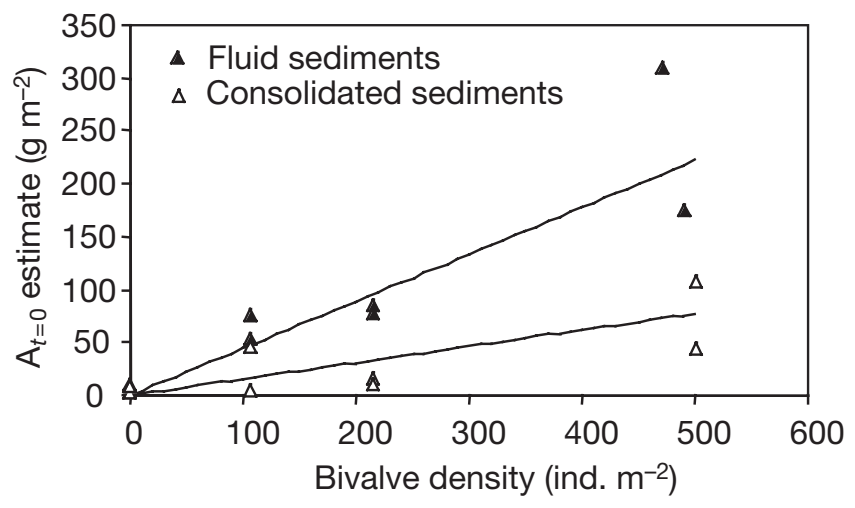

Fig. 5. Computed estimates of $A_{t=0}$ (i.e. sediment quantity initially comprised within fluff layer) plotted against the Scrobicularia plana density in flume experiments with fluid or consolidated sediments 

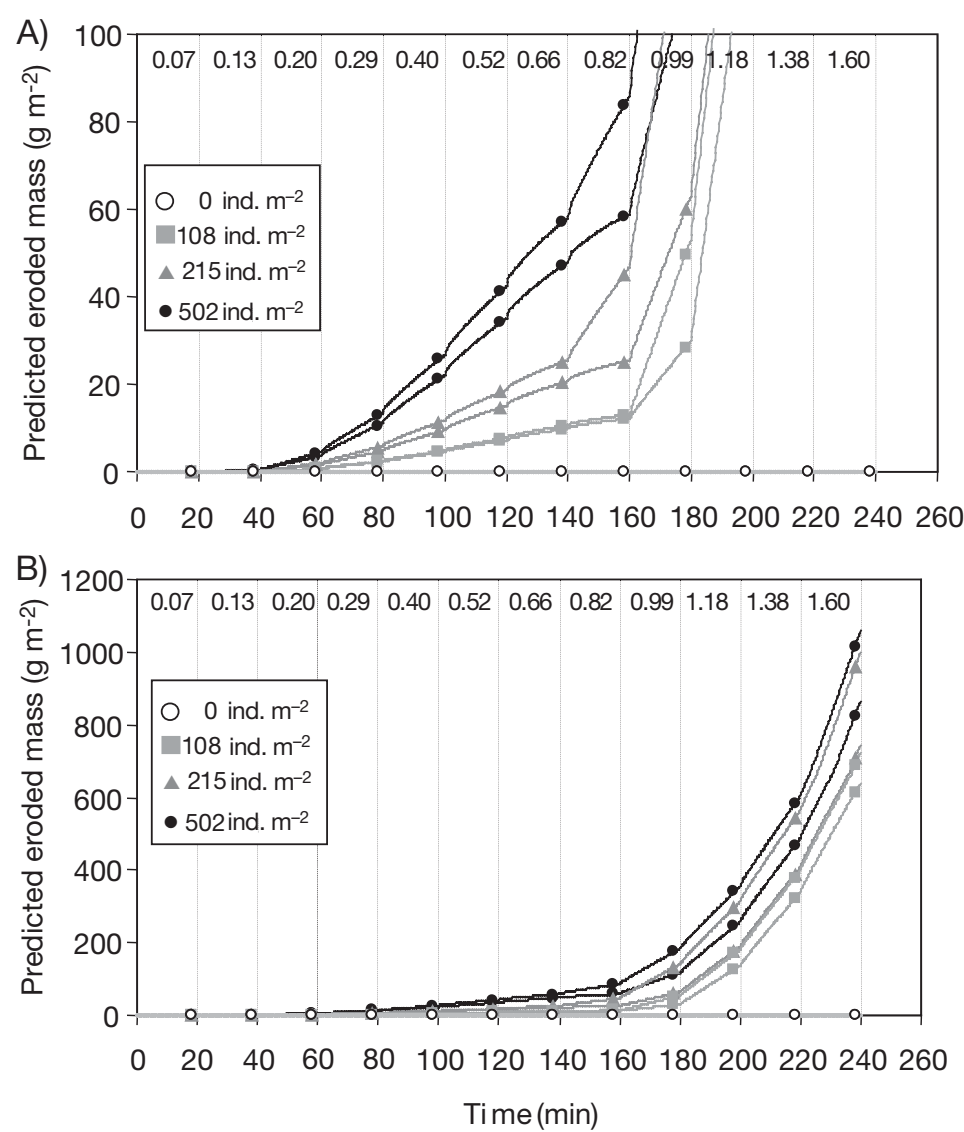

Fig. 6. Model output of the eroded sediment mass as a function of time in response to the step-by-step increasing of bed shear stress for fluid sediments: (A) focus on fluff layer erosion, with a $y$-axis scale of 0 to $100 \mathrm{~g} \mathrm{~m}^{-2}$, and (B) overall view of predicted erosion kinetics

also correctly reproduced for consolidated sediments (Fig. 7). The agreement between observation and prediction was fairly good within fluff layer erosion periods for fluid and consolidated sediments (Fig. 8A). The model slightly underestimated eroded mass, especially for the maximum bivalve density of 502 ind. $\mathrm{m}^{-2}$, but was reliable enough to reproduce the bed erosion of fluid sediments (Fig. 8B). In contrast, no bed erosion was predicted for consolidated sediments. This should not be considered a failure of the model; the question of bed erosion of consolidated sediments cannot be examined in detail in the present study, because the range of applied bed shear stresses was not great enough in flume. Indeed, amongst the 2 replicates, with densities of 215 and 502 ind. $\mathrm{m}^{-2}$, only 1 experiment displayed bed erosion. Bed erosion of consolidated sediments cannot be evaluated correctly due to these discrepancies between replicates, and the model was therefore not developed to reproduce these uncertain effects.
One of the original features of the erosion function is the direct incorporation of dry density to compute erosion rates (see the equation for bed erosion in Table 2). This equation was used by Orvain et al. (2003) to reproduce bed erosion of fluid sediments in a previous erosion study that used the same experimental design and sediment stock. The validity of this erosion function could not be tested using the present dataset, since the shear stress range applied did not induce bed erosion in the absence of bioturbating organisms. Nevertheless, including the dry density dependence of the erosion rate within the model reproduced the experimental data better than minimisation tests in which the $\gamma$ parameter was fixed at 0 . The improved fit attributed to $\gamma$ is associated with small variations in the measured dry density values for each test bed (Table 1).

Finally, Table 2 presents the model with 2 subcomponents. First, equations are shown for fluff layer formation and erosion with only 5 parameters ( 3 of them were minimised and 2 taken from literature). This subcomponent can be used as a single model to simulate fluff layer erosion. Secondly, equations are shown for bed erosion that occurs after fluff layer erosion. This group of equations is used in the 1-dimensional vertical design, and 7 parameters are required ( 5 of them were minimised and 2 taken from literature). Two of these parameters are used to describe the dry density dependence of the critical shear stress for bed erosion, and 2 others are used to describe the bivalve density effect.

Each of the 2 parts of the model can be used separately, and the complete version is only required to simulate the succession of fluff layer erosion and bed erosion.

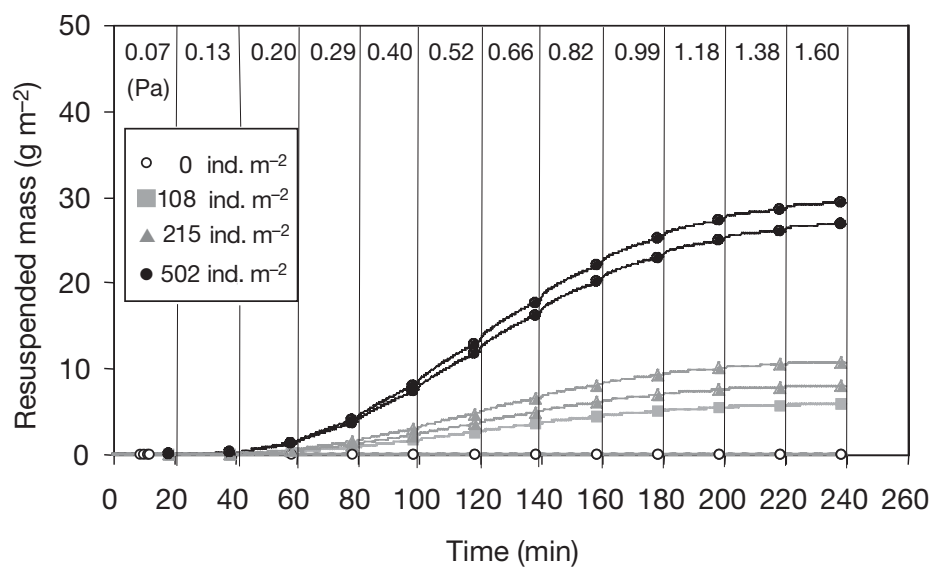

Fig. 7. Model output of eroded sediment mass as a function of time in response to the step-by-step increasing of bed shear stress for consolidated sediments 


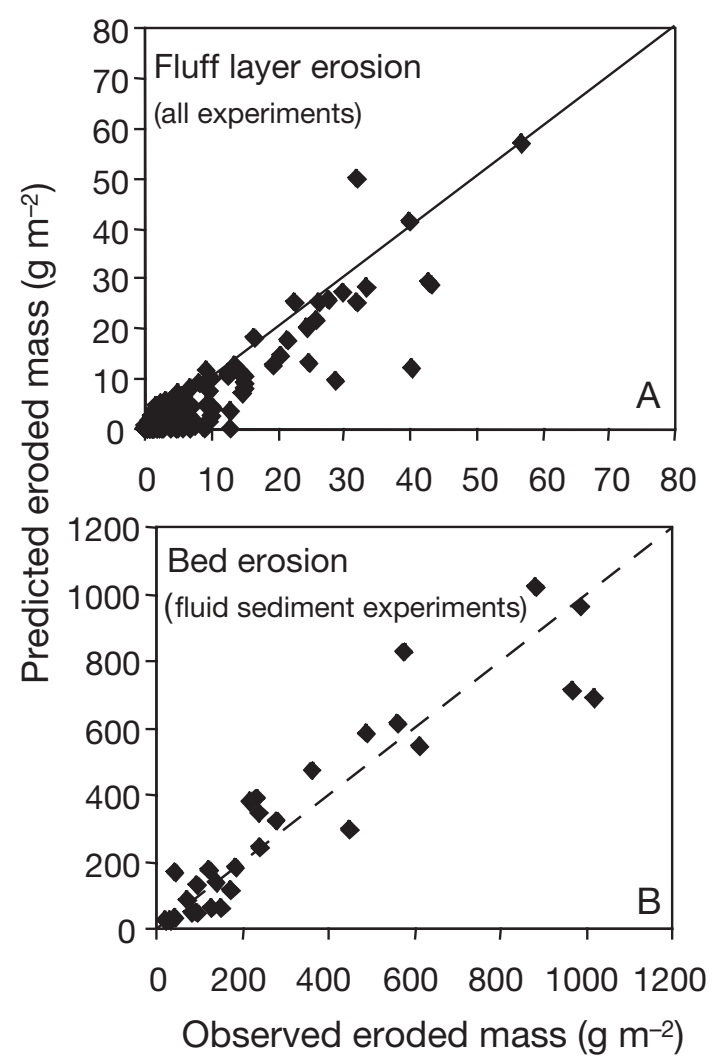

Fig. 8. Predicted values against observed data of the mean eroded mass per shear stress step: (A) for fluff layer erosion (all experiments) and (B) for subsequent bed erosion (fluid sediment experiments). Solid lines are the regression lines $\left(y=0.848 x ; r^{2}=0.85\right.$ for fluff layer erosion; $y=0.947 x ; r^{2}=0.84$

for bed erosion) and the dashed lines represent $y=x$

\section{DISCUSSION}

\section{Bioturbation and sediment transport}

Critical bed shear stress has been found experimentally to be related to sediment density (Migniot 1968, Teisson et al. 1993, Amos et al. 1997, Mitchener \& O'Brien 2001). There are many studies that highlight the importance of using a depth gradient of bed shear stress for scaling the erosion rate (Piedra-Cueva \& Mory 2001, Sanford \& Maa 2001), and there is a general consensus that consolidation processes govern this gradient (e.g. Teisson et al. 1993).

One-dimensional vertical models provide useful tools for examining bed erodibility, because they allow, e.g., a depth gradient of critical bed shear stresses to be used (or a difference in critical bed shear stress for 2 different erosion phases). Typically, fluff layer erosion can be identified as a preliminary erosion phase that occurs before general bed failure. The fluff layer has been included as a new compartment, present at the sediment-water interface, in the 1-dimensional vertical model of sediment transport. Bed erosion is not affected by the presence of a fluff layer within the model.

The results of the present study indicate that (1) erosion rates of the fluff layer depend on bioturbation intensity, which is, in turn, dependent on bivalve density and sediment density, and (2) critical thresholds of the subsequent bed erosion decreased drastically due to locally enhanced bed roughness that was created by the siphon activity of bivalves. Unfortunately, it was impossible to discriminate between bed shear stress modification and critical threshold alteration in our experiments. For the sake of simplicity, we therefore attributed the shift in initiation of erosion to an alteration of the critical threshold within the model. This simplification has the advantage of not considering variation in bed shear stress by organisms, a process which appears very complex and would require further model upscaling.

The common bivalve Scrobicularia plana is a euryhaline species which inhabits intertidal sediments at very high densities. In general, its distribution over intertidal mudflats remains confined to upper shore levels (Hughes 1970a, Ysebaert \& Meire 1999). This is the case on the Montportail-Brouage mudflat in Marennes-Oléron Bay, where densities of this dominant species can reach seasonal extremes at upper shore levels (Sauriau et al. 1989, Orvain et al. 2003). $S$. plana behaves, most of the time, as a deposit feeder, because of long submersion periods at upper shore levels of the mudflat.

Our results suggest that Scrobicularia plana has a large potential impact on sediment budgets by enhancing erosion, and seasonal population density variations are thus likely to play an important role in sediment dynamics. Natural populations of $S$. plana in Marennes-Oléron Bay could be a prime factor in maintaining the high sediment exchange rates at upper shore levels of the intertidal mudflats in this ecosystem, where the supply of deposited sediments is known to be large (e.g. Le Hir et al. 2000). Wood \& Willows (2002) showed that another species belonging to the same superfamily (Tellinacea), Macoma balthica, has important effects on sediment budgets and geomorphologic changes in intertidal areas.

While the amount of sediment within the fluff layer for Hydrobia ulvae was linked to the extent that crawl tracks covered the sediment surface (Orvain \& Sauriau 2002), the fluff layer was created through pseudofaeces production in Scrobicularia plana. Hughes (1970b) and Worrall et al. (1983) addressed energy budgets of $S$. plana, where ingestion functions were controlled by temperature. Since the extent of biotur- 
bation is directly connected to pseudofaeces production, a key issue of this study is to reinforce links between ecophysiological models and sediment transport models. This could imply an accurate assessment of the sediment supply into the water column under the control of spatio-temporal variations mediated by bioturbation processes.

\section{Interspecific comparison of erosion function}

According to Orvain et al. (2003), low amounts of resuspended mass (up to about $50 \mathrm{~g} \mathrm{~m}^{-2}$ ) are associated with the breakdown of Hydrobia ulvae tracks during the fluff layer erosion phase. Scrobicularia plana deposit feeding leads to higher values of eroded mass (up to $250 \mathrm{~g} \mathrm{~m}^{-2}$ for the maximum density of 502 ind. $\mathrm{m}^{-2}$ ) during the fluff layer erosion phase. This value is on the same order of magnitude as the maximum eroded mass measured under the influence of 502 ind. $\mathrm{m}^{-2}$ of Macoma balthica, as reported in Willows et al. (1998). This species also belongs to the superfamily of Tellinacea and alters sediment transport in a similar way to $S$. plana, but adults are smaller in size, have shorter siphon lengths and a smaller feeding radius (Zwarts et al. 1994).

In the model of sediment transport under the influence of Hydrobia ulvae, there was a need to express variable resistance to erosion within the fluff layer due to surface heterogeneities that were attributed to track formation processes (Orvain et al. 2003). A nil value, however, of the rate of increase of $\tau_{\text {fluff }}(\delta)$ was found in the present study, implying that no variation of $\tau_{\text {fluff }}$ would be required for Scrobicularia plana. In contrast to the $H$. ulvae experiments, this result means that there was an absence of asymptotic patterns in the eroded mass within the observed steps (Figs. 1A \& 2A); this could be due to direct biological resuspension of pseudofaeces during shear stress increases, since the bivalves continued to expel pseudofaeces by their extended inhalant siphons, which were extended several centimetres above the sediment-water interface (visual observation). A constant supply of biologically resuspended sediment would provide a reasonable explanation for the lack of asymptotic pattern within the 20 min long shear stress steps. In addition to surface fluff layer resuspension, the pseudofaeces ejection by $S$. plana supplies sediment to the water column when current velocity was applied. However, asymptotic patterns within the 20 min long shear stress steps were clearly obtained by Willows et al. (1998), who investigated Macoma balthica, while this species was also responsible for direct bioresuspension. This suggests that the extent of bioresuspension might be higher for $S$. plana than for $M$. balthica (a species which is functionally similar to $S$. plana), but direct comparison should be undertaken to elucidate this question. If direct bioresuspension is important for these species, further development of the model should be undertaken.

Studying fluff layer erosion with Macoma balthica, Willows et al. (1998) demonstrated that the amount of resuspended sediment approached an upper limit at higher current velocities. When no bed erosion occurred during our experiments (i.e. for the most consolidated sediments, Fig. 2B), we also obtained a decrease in eroded mass as bed shear stress increased. In a previous study on Hydrobia ulvae bioturbation, the reduction of resuspension rates at higher velocities was less clear (Orvain et al. 2003), which suggests that $H$. ulvae tracks may be more resistant to higher shear stresses than bivalve pseudofaeces. The surface area:height ratio of the fluff layer is considerably higher for H. ulvae compared to that for S. plana, suggesting differences between the resuspension properties of the 2 fluff layers exist. $S$. plana pseudofaeces may accumulate in piles of discrete aggregate particles of up to $2 \mathrm{~cm}$ in height, which are subjected locally to strong accelerating stresses. In contrast, $H$. ulvae crawl tracks are comparatively flat, and possibly maintain some structural continuity with the underlying sediment bed.

\section{Interspecific comparison of fluff layer formation}

The major differences between both species are the mechanisms involved in fluff layer formation, and these differences can be compared in terms of the coverage rate of a sedimentary surface (Fig. 9). Motile grazers such as Hydrobia ulvae produce crawl tracks that progressively cover the surface of the sediment (Fig. 9A). Since movement of Hydrobia species is random, the probability of creating new tracks at a specific time depends on the amount of surface that has already been bioturbated (Orvain \& Sauriau 2002). The rate of increase of track-covered area (equation in Fig. 9) depends on the product of the bioturbation time $(t$, in $\mathrm{h})$, animal density $\left(n\right.$, in ind. $\mathrm{m}^{-2}$ ) and the individual crawling rate $\left(a\right.$, in $\mathrm{m}^{2}$ ind.$\left.^{-1} \mathrm{~h}^{-1}\right)$. The sediment area covered by tracks $(\Phi)$ is expressed as a proportion of the whole sediment in percent $\left(\Phi_{\max }=100 \%\right)$. A conversion from $\phi$ into sediment mass comprised in a fluff layer $A_{t=0}$ (in $\mathrm{kg} \mathrm{m}^{-2}$ ) has been proposed by Orvain et al. (2003). As a result, the combined effects of bioturbation time and snail density on sediment area covered by tracks are symmetric (Fig. 9C), and an increase in bioturbation time or snail density in the same proportions would have a similar effect on sediment resuspension. 
A)

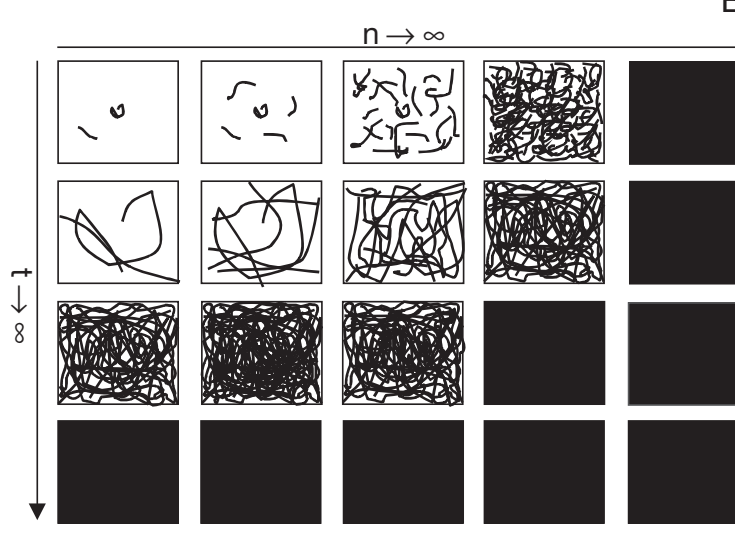

$$
\Phi=\Phi_{\text {MAX }} \times\left(1-\mathrm{e}^{- \text {ant }}\right)
$$

C)

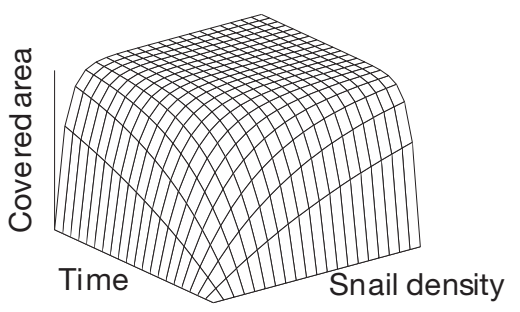

B)

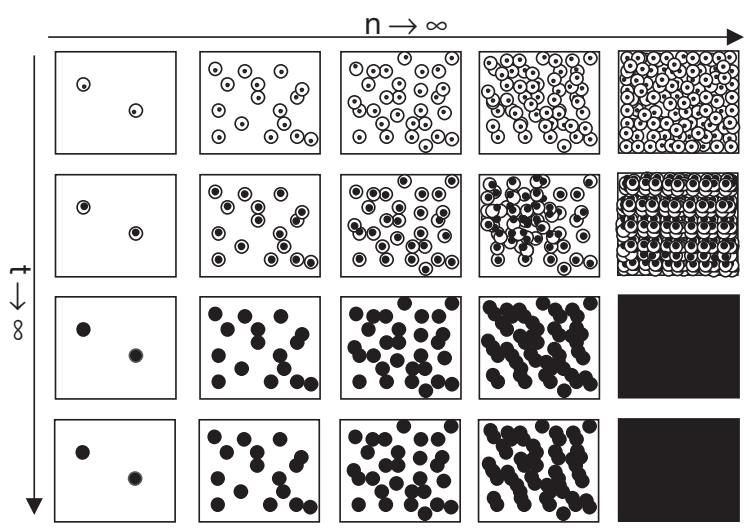
$\Phi=\Phi_{\text {MAX }} \times\left(1-\mathrm{e}^{-C n}\right) \times\left(1-\mathrm{e}^{-\times \sum_{i} n_{i} a W_{i}^{\mathrm{b}}} / \rho_{\mathrm{btb}} \times n_{\mathrm{btb}}{ }^{t}\right)$

D)

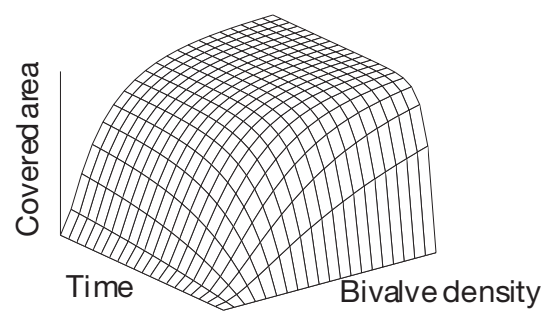

Fig. 9. Schematic representation of areas covered by fluff layer sediment ( $\phi$ ): (A) for Hydrobia ulvae (solid lines represent animal tracks) and (B) for Scrobicularia plana (white circles represent feeding individual areas; black circles represent effective areas covered by pseudofaeces). Plots (C) and (D) display the theoretical changes between areas covered versus bioturbation time and animal density for $H$. ulvae and $S$. plana, respectively

Sediment bioturbation by Scrobicularia plana occurs as bottom sediments are ingested through the inhalant siphon, sorted on the palps into comestible and noncomestible fractions, and the non-comestible material is subsequently expelled as pseudofaeces (Hughes 1970b). As a result, the local feeding area around an individual $\left(\Phi_{\mathrm{IND}}\right.$, in $\left.\mathrm{m}^{2}\right)$ is progressively covered by pseudofaeces in increasing proportions (Fig. 9B), and, as the search is random (Hughes 1970a), the probability for an animal to take up sediment from an uncovered area decreases with time. Within a local feeding area of an individual, the sediment area covered by pseudofaeces reads:

$$
\Phi=\Phi_{\text {IND }} \times\left(1-\mathrm{e}^{-a_{\text {IND }}}\right)
$$

This expression is equivalent to the expression for motile grazers (Orvain \& Sauriau 2002; Fig. 9). The rate of increase of the sediment area covered by pseudofaeces $\left(a_{I N D}, h^{-1}\right)$ is directly related to pseudofaeces production depending on shell size (Eqs. 2 to 4). The rate of pseudofaeces production (in $\mathrm{g}$ ind. ${ }^{-1}$ $\mathrm{h}^{-1}$ ) is the weight of pseudofaeces produced per individual and per hour (see Eqs. 2 to 4). We can convert this expression from mass into area by divid- ing by the sediment concentration within pseudofaeces $\left(\rho_{b t b}\right.$ ind. $\left.\mathrm{m}^{-3}\right)$ and the height of pseudofaecal piles $\left(h_{\mathrm{btb}}\right.$, in $\left.\mathrm{m}\right)$ :

$$
a_{\mathrm{IND}}=\sum_{i} n_{i} a W_{i}^{b} / \rho_{\mathrm{btb}} \times h_{\mathrm{btb}}
$$

The feeding areas of individuals may overlap (because of the absence of observed territoriality in this species); thus, the bivalve density is also included as a variable in Eq. (11).

For stationary bivalves, the maximum area, which is available for deposit feeding, also depends on the animal density and, to a lesser extent, on shell size, because the feeding radius of an individual increases with shell size (Zwarts et al. 1994). Therefore, the formulation for the maximum available feeding area can be described with another von Bertalanffy expression depending on bivalve density and including a parameter related to individual feeding areas $\left(C\right.$, in $\mathrm{m}^{2}$ ind. ${ }^{-1}$ ).

$$
\Phi_{\mathrm{IND}}=\Phi_{\mathrm{MAX}} \times\left(1-\mathrm{e}^{-C n}\right)
$$

The complete expression for the surface covered by pseudofaeces becomes: 


$$
\Phi=\Phi_{\mathrm{MAX}} \times\left(1-\mathrm{e}^{-C n}\right) \times\left(1-\mathrm{e}^{-\left(\sum_{i} \sum_{n_{i} \mathrm{a} W_{i}}^{b} / \rho_{\mathrm{btb}} \times h_{\mathrm{btb}}\right) t}\right)
$$

and the corresponding sediment mass is:

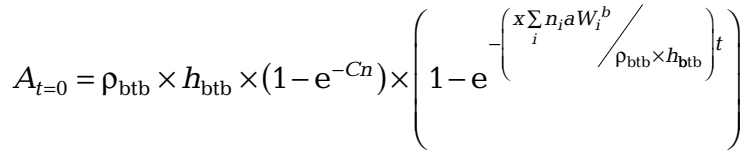

As a result, there is an asymmetry between time and density effects for stationary animals in favour of density (Fig. 9D). This may explain why Willows et al. (1998) remarked that time effects could be neglected in comparison to density effects for Macoma balthica.

Willows et al. (1998) obtained an asymptotic increase of resuspension levels with naturally occurring bivalve densities. Their results are consistent with our theoretical assumptions (Eq. 12 and Fig. 9D) about fluff layer formation through pseudofaeces production. We, however, obtained a linear relationship for Scrobicularia plana (Fig. 5) for the density range tested in our flume experiments, a range in which the maximum was less than the maximum density reported for natural populations (ca. 2000 ind. $\mathrm{m}^{-2}$ ). This may be due to us avoiding interference (overlap) between the feeding activities of neighbours and should be considered an experimental bias. Indeed, overlapping is the basic process underlying the asymptotic pattern of resuspended mass as a function of bivalve density.

\section{CONCLUSIONS}

Pearson (2001) in his recent synthesis has reviewed the ways in which the roles of bioturbators have been partitioned into functional groups, and highlighted the utility of such groupings in assessing interactions between the sediment and the organisms.

The most essential question addressed by our study is how the 1-dimensional vertical model presented here can be generalised to a more complex and multispecific assemblage using a common structure. The same formulation of the erosion function was found to be appropriate for Hydrobia ulvae as well as Scrobicularia plana, demonstrating that both species can be described within the same model design. Separate parameter sets must be used, however, to reproduce erosion kinetics, and different equations are also required to account for the contribution of each species to fluff layer formation. We suggest that 1 type of equation (Fig. 9), based on track formation mechanisms, is appropriate for sediment interface grazers (such as the mud snail H. ulvae), and a second type of equation
(Eq. 12) is better suited for subsurface and stationary bivalves, such as $S$. plana. These models could be considered as 2 elementary components of an intertidal ecosystem sediment transport model. This classification of bioturbators should be useful in a functional approach to the study of sediment erodibility by following an approach similar to that proposed by Francois et al. $(1997,2002)$ or Boudreau (1997) for models of sediment reworking. However, effects of deposit feeders on sediment resuspension are non-linear, and single-species models cannot be applied directly to predict community effects. It is now crucial to examine, through experiments and model developments, the effects of several species put together on a sediment surface to consider inter-specific relationships in an attempt to propose a model for the prediction of community effects.

Acknowledgements. The Regional Council of Poitou-Charentes and Ifremer have financially supported the study by a doctoral grant. And many thanks to G. Guillou, M. Prineau, M. Bréret and M. Guillaut for assistance in the laboratory.

\section{LITERATURE CITED}

Amos CL, Feeney T, Sutherland TF, Luternauer JL (1997) The stability of fine-grained sediments from the Fraser River Delta. Estuar Coast Shelf Sci 45:507-524

Andersen TJ (2001) Seasonal variation in erodability of two temperate, microtidal mudflats. Estuar Coast Shelf Sci 53: $1-12$

Andersen TJ, Jensen KT, Lund-Hansen L, Mouritsen KN, Pejrup M (2002) Enhanced erodability of fine-grained marine sediments by Hydrobia ulvae. J Sea Res 48:51-58

Beaulieu SE, Smith KL (1998) Phytodetritus entering the benthic boundary layer and aggregated on the sea floor in the abyssal NE Pacific macro- and microscopic composition. Deep-Sea Res Part B 45:781-815

Blanchard GF, Sauriau PG, Cariou-Le Gall V, Gouleau D, Garet MJ, Olivier F (1997) Kinetics of tidal resuspension of microbiota: testing the effects of sediment cohesiveness and bioturbation using flume experiments. Mar Ecol Prog Ser 151:17-25

Boudreau BP (1997) A one-dimensional model for bedboundary layer particle exchange. J Mar Syst 11:279-303

Brenon I, Le Hir P (1999) Modelling the turbidity maximum in the Seine estuary (France): identification of formation processes. Estuar Coast Shelf Sci 49:525-544

Cugier P, Le Hir P (2002) Development of a 3D hydrodynamic model for coastal ecosystem modelling application to the plume of the Seine River (France). Estuar Coast Shelf Sci 55:673-695

Davis WR (1993) The role of bioturbation in sediment resuspension and its interaction with physical shearing. J Exp Mar Biol Ecol 171:187-200

Efron B (1979) The 1977 Rietz lecture. Bootstrap methods: another look at the jack-knife. Ann Stat 7:421-449

François F, Poggiale JC, Durbec JP, Stora G (1997) A new approach for the modelling of sediment reworking induced by a macrobenthic community. Acta Biotheor 45: 295-319

François F, Gérino M, Stora G, Durbec JP, Poggiale JC (2002) 
Functional approach to sediment reworking by galleryforming macrobenthic organisms: modeling and application with the polychaete Nereis diversicolor. Mar Ecol Prog Ser 229:127-136

Galois R, Blanchard G, Seguignes M, Huet V, Joassard L (2000) Spatial distribution of sediment particulate organic matter on two estuarine intertidal mudflats: a comparison between Marennes-Oléron Bay (France) and the Humber estuary (UK). Cont Shelf Res 20:1199-1217

Graf G, Rosenberg R (1997) Bioresuspension and biodeposition: a review. J Mar Syst 11:269-278

Grant J (1983) The relative magnitude of biological and physical reworking in an intertidal community. J Mar Res 41: 673-689

Grant J, Daborn G (1994) The effects of bioturbation on sediment transport on an intertidal mudflat. Neth J Sea Res 32: $63-72$

Hall SJ (1994) Physical disturbance and marine benthic communities: life in unconsolidated sediments. Oceanogr Mar Biol Annu Rev 32:179-239

Hughes RN (1969) A study of feeding in Scrobicularia plana. J Mar Biol Assoc UK 49:805-823

Hughes RN (1970a) Population dynamics of the bivalve Scrobicularia plana (da Costa) on an intertidal mud-flat in North Wales. J Anim Ecol 39:333-356

Hughes RN (1970b) An energy budget for a tidal-flat population of the bivalve Scrobicularia plana (da Costa). J Anim Ecol 39:357-379

Jumars PA, Nowell ARM (1984) Effects of benthos on sediment transport: difficulties with functional grouping. Cont Shelf Res 3:115-130

Le Hir P, Roberts W, Cazaillet O, Christie M, Bassoulet P, Bacher C (2000) Characterization of intertidal flat hydrodynamics. Cont Shelf Res 20:1433-1459

Migniot C (1968) Etude des propriétés physiques de différents sédiments très fins et de leur comportement sous des actions hydrodynamiques. Houille Blanche 7:591-620

Mitchener HJ, O'Brien DJ (2001) Seasonal variability, erodability and properties on a macrotidal mudflat, Peterstone Wentlooge, Severn Estuary, UK. In: McAnally WH, Mehta AJ (eds) Coastal and estuarine fine sediment processes. Elsevier, Amsterdam, p 301-322

Nelder JA, Mead R (1965) A simplex method for function minimization. Comput J 7:308-313

Nowell ARM, Jumars PA, Eckman JE (1981) Effects of biological activity on the entrainement of marine sediments. Mar Geol 42:133-153

Orvain F, Sauriau PG (2002) Environmental and behavioural factors affecting activity in the intertidal gastropod Hydrobia ulvae. J Exp Mar Biol Ecol 272:191-216

Orvain F, Le Hir P, Sauriau PG (2003) A model for initial resuspension of bioturbated layers and ensuing bed erosion. J Mar Res 61:821-849

Editorial responsibility: Otto Kinne (Editor-in-Chief), Oldendorf/Luhe, Germany
Partheniades E (1965) Erosion and deposition of cohesive soils. J Eur Hydrol 91:105-139

Pearson TH (2001) Functional group ecology in soft-sediment marine benthos: the role of bioturbation. Oceanogr Mar Biol Annu Rev 39:233-267

Piedra-Cueva I, Mory M (2001) Erosion of a deposited layer of cohesive sediment. In: McAnally WH, Mehta AJ (eds) Coastal and estuarine fine sediment processes. Elsevier, Amsterdam, p 41-51

Rhoads DC, Young DK (1970) The influence of deposit-feeding organisms on sediment stability and community trophic structure. J Mar Res 28:150-178

Rhoads RC (1974) Organism-sediment relations on the muddy sea floor. Oceanogr Mar Biol Annu Rev 12:263-300

Sanford LP, Maa JPY (2001) A unified erosion formulation for fine sediments. Mar Geol 179:9-23

Sauriau PG, Mouret V, Rincé JP (1989) Organisation trophique de la malacofaune benthique non cultivée du bassin ostréicole de la baie de Marennes-Oléron. Oceanol Acta 12:193-204

Shaikh MA, Meadows A, Meadows PS (1998) Biological control of avalanching and slope stability in the intertidal zone. In: Black KS, Paterson DM, Cramp A (eds) Sedimentary processes in the intertidal zone. Geol Soc Am Spec Pap 139:309-329

Teisson C, Ockenden M, Le Hir P, Kranenburg C, Hamm L (1993) Cohesive sediment transport processes. Coast Eng 21:129-162

Widdows J, Brinsley MD, Elliott M (1998) Use of in situ flume to quantify particle flux (deposition rates and sediment erosion) for an intertidal mudflat in relation to changes in current velocity and benthic macrofauna. In: Black KS, Paterson DM, Cramp A (eds) Sedimentary processes in the intertidal zone. Geol Soc Am Spec Pap 139:85-97

Willows RI, Widdows J, Wood RG (1998) Influence of an infaunal bivalve on the erosion of an intertidal cohesive sediment: a flume and modeling study. Limnol Oceanogr 43: $1332-1343$

Worrall CM, Widdows J, Lowe DM (1983) Physiological ecology of three populations of the bivalve Scrobicularia plana. Mar Ecol Prog Ser 12:267-279

Wood R, Widdows J (2002) A model of sediment transport over an intertidal transect, comparing the influences of biological and physical factors. Limnol Oceanogr 47: 848-855

Ysebaert T, Meire P (1999) Macrobenthos of the Schelde estuary: predicting macrobenthic species responses in the estuarine environment: a statistical analysis of the Schelde estuary macrobenthos within the ECOFLAT project. Report IN 99/19. Institute of Nature Conservation, Brussels

Zwarts L, Blomert AM, Spaak P, de Vries B (1994) Feeding radius, burying depth and siphon size of Macoma balthica and Scrobicularia plana. J Exp Mar Biol Ecol 183:193-212

Submitted: August 8, 2003; Accepted: August 17, 2004

Proofs received from author(s): January 10, 2005 